\title{
Perceptual Phenomena Associated with Spontaneous Experiences of After-Death Communication: Analysis of visual, tactile, auditory and olfactory sensations
}

\author{
Marjorie Woollacott, PhD; Chris A. Roe, PhD; Callum E. Cooper, PhD; David \\ Lorimer, MA; \& Evelyn Elsaesser
}

\begin{abstract}
The purpose of this study was to create a detailed characterization of the nature of the sensory perceptions associated with after-death communication. A primary aim was to determine if perceptions of after-death communication (ADC) support one or more of three hypotheses: 1 ) they are the result of hallucinations or day-to-day thoughts about the deceased;2) they are subjective phenomena reflecting the extrasensory perception of remote events; or 3) they constitute objective phenomena, perceived more solidly, as if within the physical world. Methods: The study included a quantitative analysis and qualitative first-person narrative description of part of the data set from a detailed questionnaire study (991 viable cases) investigating the phenomenology of spontaneous ADCs. Results and Conclusions: A majority of respondents reported that ADCs were distinctly different from simple thoughts about the deceased. Specifically, relative distribution of ADCs across the senses was $46 \%$ visual, $44 \%$ auditory, $48 \%$ touch, and $28 \%$ olfactory, with $34 \%$ sensing the presence of the deceased without input from the five senses. ADCs often were perceived as external and having properties of the material world (e.g., solidity, tactile qualities). Even the more nebulous 'sense of presence' cases were perceived as having a distinct location in space and as being identifiable as a specific deceased presence despite the lack of sensory cues. These elements are more compatible with hypotheses 2 and 3 than hypothesis 1.
\end{abstract}

\section{Key words: after-death communication, ADC, bereavement, telepathy, anomalous experience, sensed-presence}

\section{Introduction}

When persons experience the death of a friend or loved one, it is very often devastating. Even if they are expecting their loved one's passing, they frequently go through a grieving process that involves finding ways to integrate this event into their core beliefs about the meaningfulness of the world. ${ }^{1}$ One key phenomenon that research shows can play a part in processing this physical loss is the experience of sensing the presence of the deceased person, either at the moment of their death or some time afterward..$^{1-3}$ These experiences of after-death communications $\left(\mathrm{ADCs}^{4}\right)$ termed as such to reflect the manner in which experiencers typically make sense of them, have been found to be relatively common. Research studies on the general population estimate that $30-35 \%$ of 
persons report experiencing an $\mathrm{ADC}^{3,5}$ and this most often occurs within a year of the passing of their loved one. ${ }^{3}$ Other surveys of persons, in particular mourners, report that between $50 \%$ and $60 \%$ had one or several ADCs. ${ }^{6-9}$

Research into the nature of ADCs has been ongoing since the late $1800 \mathrm{~s}^{4,8,10-13}$ (see Streit$\mathrm{Horn}^{3}$ for a review). These studies have shown that ADCs occur across different age groups, gender, education level, cultural background and level of religious orientation, thus giving evidence that ADCs happen consistently across all groups within society. ${ }^{3,14}$ Research also suggests that ADCs tend to occur unexpectedly and are typically perceived as positive and comforting to the individual perceiver. ${ }^{2,15-16}$

Despite their positive nature, many persons who have experienced ADCs express a reluctance to share them with friends, family or bereavement counselors, due to a fear that they will be ridiculed, considered mentally ill or that it will have a negative impact on their professional career. ${ }^{17-18}$ This has led ADC researchers to recommend increasing the awareness of healthcare workers, counselors and the general public regarding the nature of ADCs in order to foster understanding and acceptance. Many researchers, including Judy and Bill Guggenheim, ${ }^{4}$ pioneers in the study of ADCs in the U.S. and Canada, have noted that a large number of the individuals they interviewed expressed hope that readers of the research would benefit from learning more specifically of the nature of their ADCs. They hoped that this would prevent others from the suffering and confusion they went through when family, friends or healthcare workers did not accept the reality or the meaningfulness of their experience. ${ }^{3}$

As early as 1886, Gurney and colleagues recorded over 100 cases of people's encounters with the deceased, referring to them as "hallucinations of the sane."10 This research, published over 130 years ago, very carefully described and analyzed the ADCs, noting that within a given sensory modality, such as vision, an ADC could have varying degrees of what they called internalization vs. externalization, ranging from a purely internal representation as is seen by the "mind's eye," to an actual percept that seems to take place in the physical world and is mediated by the senses, for example in obscuring other objects in the vicinity or casting shadows. ${ }^{10-11}$

Since this original detailed study was reported in the late 1800s, phenomenological research quantifying the nature of the sensory experience has not been as prevalent, and most articles on sensory aspects of ADCs have treated the phenomenon more generally, simply noting the incidence of different forms of sensory experience within the population sampled. ${ }^{9,18-19}$ Rees, ${ }^{18}$ for example, notes that of the total population interviewed $(\mathrm{n}=293), 39 \%$ experienced simply a feeling of the presence, $14 \%$ saw, $13.3 \%$ heard, and $2.7 \%$ were touched by the deceased. 
Within the scientific community there is no consensus about the origin of ADCs, or the sensory-perceptual phenomenology that is associated with them. At least three hypotheses could contribute to an explanation of this phenomenon. A first hypothesis, based on a materialist or reductionist point of view, suggests that ADCs are just thoughts (mental constructs) - reflecting either normal imaginal processes, or aberrant thoughts, such as aberrant hallucinations caused by grief or mental unbalance - and that any attributions of ADC sensory phenomenology as sensory stimuli encountered in the external physical world represent failures of reality monitoring. Though this is a prevalent interpretation of ADCs among scientists, research suggests that percipients of ADCs strongly disagree with this view. $8,12,27-28$

A challenge to this hypothesis comes from research showing that during some ADCs, percipients receive novel information to which they have had no previous access. ${ }^{4,8,10,12}$ In fact, one way of investigating the nature of ADCs is with reference to information that is communicated and the level of veracity of this information. Regarding the first hypothesis, the view would be that no new information can be communicated in an $\mathrm{ADC}$, as this is an internally generated thought/hallucination.

A second hypothesis is based on the view that consciousness is fundamental (i.e., it can survive death of the body) and that nonlocal communication (communication between individuals who are not spatially or temporally connected) is possible. ${ }^{20-21}$ This view suggests that some portion of ADCs are actual instances of communication between the deceased and the percipient that are telepathically received. In this hypothesis, sensory phenomena are part of the communication itself; however, they are not realized externally in the form of a distal object that can be detected through normal sensory means, but telepathically, by creating a perception or externally produced thought in the mind of the perceiver. ${ }^{8}$

Finally, a third hypothesis is that the ADC experience is not only cognitive in nature, but results from the creation of a subtle or energetic form that materializes for a short period of time. In this case, sensory phenomena associated with ADCs are viewed as accurate perceptions of distal stimuli that are apprehended through the senses or through a form of extrasensory perception at a distance (e.g., in perceiving subsequently verified events in the dying person's home). Though the second and third hypotheses described above are less accepted, they are better able to explain the phenomenon of verified receipt of previously unknown information by the percipient. ${ }^{4,10}$ 
Since there are only a limited number of research studies that have explored the sensory phenomenology of ADCs, the primary aim of this study is to examine in more detail the nature of the sensations described by the ADC percipient. It is hoped that a clearer understanding of the sensory phenomenology of ADCs will shed light on the extent to which ADC perceptions appear to support one or more of the three hypotheses: that they are the result of day-to-day thoughts about the deceased; that they are subjective

phenomena that reflect the extrasensory perception of remote events; or that they constitute objective phenomena, perceived more solidly, as if within the physical world.

We hope that this more detailed and extensive documentation of the characteristics of sensory information perceived as part of an ADC will add to the already existing data supporting the normalcy and the meaningfulness of these events and thereby increase the acceptance of ADCs within our culture.

\section{Methods}

This paper gives a quantitative analysis and qualitative first-person narrative description of part of the data set from a study conducted from February 2018 to January of 2020 investigating the phenomenology and impact of spontaneous afterdeath communications (ADCs). ${ }^{1}$ The project received approval from (Approval \# FHSRECSS00084).

\section{Questionnaire}

To achieve the various objectives of the project, a detailed questionnaire was created. 194 questions were developed (including follow-up questions after affirmative responses) to cover all aspects of the project, some of which are presented in this publication. The questionnaire was transposed into an online version using the Onlinesurveys platform (https://www.jisc.ac.uk/online-surveys). Online delivery was preferred because this enabled greater outreach to participants, who could be provided with a web link and allowed to complete the survey at their convenience. Additionally, it enabled the questionnaire to be designed so that it responded 'intelligently'; for example, if a respondent indicated that they had not had an auditory component to their experience they would not be asked any follow-up questions that related only to auditory experiences. Participants were free to omit any questions they preferred not to answer or which they felt were not relevant to their experience. Where appropriate,

${ }^{1}$ The study was designed and data collection was carried out by

. In the overall study there were a number of objectives. A portion of the data from the first objective, i.e., the description of the circumstances and the sensory/ perceptual experience (the phenomenology) of ADCs, will be discussed here. 
participants were able to choose 'other' rather than one of the prescribed response options, in which case they were invited to elaborate in their own words.

Participants were recruited using a purposive snowball sampling method by advertising the survey during public talks and through social media forums that specialize in ADCs and related phenomena. Interested parties were referred to a web page that gave further information about the project and provided a link to the survey.

Participants first described their ADC with their own words in a free text box. In cases where participants had experienced several ADCs, we asked them to describe only one ADC, by choosing the most significant one. The subsequent questions were presented with multiple choice options, and many included follow-up questions with a free text box. Two to three hours were necessary to fill in the questionnaire, with the possibility of completing it over multiple days. Despite this investment in time, very few participants dropped out along the way.

The questionnaire was presented in English, French, and Spanish using a secure online survey platform, and was available for six months. The link was sent out to interested parties (purposive sample) and was advertised on a website dedicated to this kind of experience. Initial pages described the project/phenomena, outlined ethical aspects, included a description of how data would be used, and were followed by a request for consent.

The questions that were included in the data set for this part of the study are on the sense of presence of the deceased individual as well as visual, auditory, olfactory and tactile perceptions related to the presence of the deceased. We also included requests for information on demographic characteristics. These included gender (male, female, other, e.g. transgender), age, educational level (university, college or equivalent [from 16-18 yrs., dealing with pre-university qualifications or vocational courses], intermediate between secondary level and university [e.g. technical training], secondary school [i.e., high school to age 16]), professional status, and marital status.

\section{Results}

\section{Demographics:}

In total there were 1,004 completed questionnaires. Initial screening removed 11 incomplete or spoiled submissions, leaving 991 viable cases (412 English, 434 French, 145 Spanish). Table 1 presents the demographics of the study participants.

\section{TABLE 1. DEMOGRAPHICS}

Gender $85 \%$ women; $14 \%$ men ( $1 \%$ other, e.g. transgender) 


\begin{tabular}{|l|l|}
\hline Age & $18-89$ years; median: 51 yrs. \\
\hline Educational Level & $\begin{array}{l}48 \% \text { university degree; } 18 \% \text { college or equivalent; } 22 \% \text { technical } \\
\text { training; } 12 \% \text { secondary school completion }\end{array}$ \\
\hline Professional status & $\begin{array}{l}59 \% \text { employed; } 21 \% \text { retired; } 4 \text { looking for work; } 4 \% \\
\text { housewife/husband; } 2 \% \text { in school/university; } 1 \% \text { temporary } \\
\text { leave; } 1 \% \text { in retraining; } 9 \% \text { none of the above }\end{array}$ \\
\hline Marital status & $\begin{array}{l}37 \% \text { married; } 14 \% \text { living with partner; } 15 \% \text { divorced; } 16 \% \text { single; } \\
12 \% \text { widowed }\end{array}$ \\
\hline
\end{tabular}

As indicated in Table 1, there was a large difference in the number of responses received from men vs. women, which is consistent with many previous research studies of this type. Previous research also indicates that men and women experience ADCs in roughly the same proportions, but women report them more.,22 The age of participants ranged between 18 and 89 years, with a median age of 51 years. The educational level of the sample was high, with $48 \%$ having a university degree. A large percentage $(80 \%)$ of the participants reported having multiple ADCs with one or several deceased persons, $34 \%$ perceived the same person each time and $11 \%$ had only one ADC.

As ADC perceptions may have varying degrees of internalization vs. externalization, ranging from a purely internal representation as is seen by the "mind's eye," to an actual percept, the questionnaire included questions to clarify the nature of the perception.

\section{Sense of Presence}

A number of questions within the study concerned whether the ADC could be described as occurring through one or more of the five major senses, or, alternatively, outside of the five senses. ${ }^{2}$ If perception (i.e., discerning or becoming conscious of) did not involve the five senses, the percipient was asked to identify, and then explain the nature of this "sense of presence." As seen in Table 2, 34\% of the respondents experienced a sense of presence that was not received through the five senses. Despite the fact that the identity and personality characteristics of the deceased were not perceived through the senses, the percipient often immediately identified the felt presence as a specific deceased person. The experience generally had a distinct beginning and end, and more than two-thirds of the individuals said that they could localize the presence in space.

In describing the sense of presence, respondents said that it seemed to have a certain density, almost physical, though invisible. One person stated, "There was a weight to

\footnotetext{
${ }^{2}$ Note that respondent reports did not include any mention of taste, the gustatory sense.
} 
the presence that I have never felt just thinking about them" (E228). ${ }^{3}$ To explore this perception further, and thus differentiate whether the experience was simply due to thinking of the person, or something truly received from beyond their own internal narrative, respondents were asked if this was similar to or different from other times they had thought about the person. Interestingly $61 \%$ said that this was different and went on to explain the differences. They noted, for example, that although they thought of the deceased often, the experience was much more real than a thought. They also felt the person in the room. One person noted that their cat reacted as well and explained, "I felt my dad physically present. My cat literally doubled in size with all her hair sticking up" (E16). Another person said, "There was a real, and unexpected, sense of her presence beside and slightly above me. Suddenly she was there, and, a few minutes later, she was just as suddenly gone again" (E319). A third said,

I went to the cemetery several months after my dad died. It was summer of 2004. I was standing at his grave and it was just turning dark. I probably shouldn't have gone that late, but missed him so much, still grieving heavily. Suddenly I was aware of someone standing behind me, and I knew it was him. He would have been concerned at me being there in the dark. (E190)

When asked if the deceased tried to communicate simply through their presence, $75 \%$ agreed, and when asked to explain, many said that the message was one of love, letting them know that the deceased was still present, and also often it felt like a form of goodbye. One person said, "She wanted me to remember all the love that she has for me that I had forgotten about, that we are connected by heart and she is always in my heart, and I'm in hers" (E353). Another ADC from a father-in-law also gave comforting information about a pet. The respondent said, "Yes, I believe that my father-in-law was trying to tell me that he was alright and that he had my dog, Maggie, ${ }^{4}$ safely with him and that she was alright" (E292).

\begin{tabular}{|l|l|l|l|}
\hline Table 2. Sense of Presence of the Deceased & \multicolumn{3}{|c|}{ Percent Responses $^{5}$} \\
\hline $\begin{array}{l}\text { Q 20. Did you perceive the presence of the deceased, without } \\
\text { seeing, hearing, or feeling a physical contact of the deceased, or } \\
\text { smelling a fragrance characteristic of the deceased? }\end{array}$ & $\begin{array}{l}34 \% \\
\text { Yes }\end{array}$ & $\begin{array}{l}60 \% \\
\text { No }\end{array}$ & $\begin{array}{l}6 \% \\
\text { Unsure }\end{array}$ \\
\hline $\begin{array}{l}\text { Q 21. Could you, without seeing the deceased, localize the presence } \\
\text { in space? (you "knew" that the deceased was behind you, next to } \\
\text { you, in front of you, etc.) }\end{array}$ & $\begin{array}{l}68 \% \\
\text { Yes }\end{array}$ & $\begin{array}{l}18 \% \\
\text { No }\end{array}$ & $\begin{array}{l}14 \% \\
\text { Unsure }\end{array}$ \\
\hline $\begin{array}{l}\text { Q 22. Did the impression of presence have a distinctive beginning } \\
\text { and end? }\end{array}$ & $\begin{array}{l}65 \% \\
\text { Yes }\end{array}$ & $\begin{array}{l}23 \% \\
\text { No }\end{array}$ & $\begin{array}{l}12 \% \\
\text { Unsure }\end{array}$ \\
\hline
\end{tabular}

\footnotetext{
${ }^{3}$ Numbers indicate cases numbers, and the letters indicate the language of the datasets.

${ }^{4}$ All names have been changed to protect the identity of respondents.

${ }^{5}$ Percentages refer to the subset of cases in which the respondent reported a sense of presence rather than the dataset as a whole. Figures are rounded to the nearest whole percent so that totals need not add up to exactly $100 \%$.
} 


\begin{tabular}{|l|l|l|l|}
\hline $\begin{array}{l}\text { Q 23 Was the feeling of the deceased's presence the same or } \\
\text { different from the times when you thought about the deceased and } \\
\text { felt that he/she was "by your side" or "in your heart"? }\end{array}$ & $\begin{array}{l}23 \% \\
\text { Same }\end{array}$ & $\begin{array}{l}61 \% \\
\text { Diff. }\end{array}$ & $\begin{array}{l}16 \% \\
\text { Unsure }\end{array}$ \\
\hline $\begin{array}{l}\text { Q 25. Did you feel that the deceased tried to communicate } \\
\text { something by his / her sheer presence? }\end{array}$ & $\begin{array}{l}75 \% \\
\text { Yes }\end{array}$ & $\begin{array}{l}11 \% \\
\text { No }\end{array}$ & $\begin{array}{l}15 \% \\
\text { Unsure }\end{array}$ \\
\hline
\end{tabular}

\section{Visual Perceptions: seeing an image externally or internally}

ADC visual perceptions varied in terms of internalization vs. externalization, ranging from a purely internal representation as is seen by the "mind's eye," to an actual visual percept. These perceptions also came in many forms, happening for example, indoors, outdoors, in a car or a plane, or in the bedroom late at night. Table 3 shows responses of participants to the questions asked regarding the nature of their visual perceptions in the ADC.

Note that $46 \%$ of the respondents "saw" the deceased; $31 \%$ of these saw the deceased when their eyes were closed (sometimes during sleep), while $60 \%$ had their eyes open. In order to better understand the nature of the ADC visual experience, one of the questions asked was "What was the consistency of the deceased?" Because in ADCs the deceased is sometimes seen as surrounded by light, percipients were also asked, "Did the deceased seem brighter than their environment, e.g. was there a light that surrounded them or emanated from them?" About a third of the respondents (35\%) reported that the deceased was surrounded or permeated by light.

\begin{tabular}{|l|l|}
\hline Table 3. Visual Perceptions of the Deceased & Percent response \\
\hline 39. Did you see the deceased? & $46 \%$ Yes \\
& $49 \%$ No \\
& $4 \%$ Unsure \\
\hline 40. When you saw the deceased were your eyes open & $60 \%$ Open \\
or closed? & $31 \%$ Closed \\
& $9 \%$ Unsure \\
\hline 41. Did you perceive the deceased as a whole or only & $60 \%$ As a whole \\
a part of the body? & $25 \%$ Only upper part of body \\
& $1 \%$ Only lower part of body \\
& $2 \%$ Unsure \\
& $12 \%$ Other \\
\hline 43. Were the feet visible? & $24 \%$ Yes \\
& $49 \%$ No \\
& $27 \%$ Unsure \\
\hline 44. How was the deceased positioned? & $74 \%$ In the center of my vision \\
& $22 \%$ In the periphery of my vision \\
& $4 \%$ Unsure \\
\hline 45.At what distance did you perceive the deceased? & $62 \%$ Within reaching distance \\
\end{tabular}




\begin{tabular}{|c|c|}
\hline & $\begin{array}{l}3 \% \text { In the distance } \\
3 \% \text { Unsure }\end{array}$ \\
\hline 46. What was the consistency of the deceased? & $\begin{array}{l}62 \% \text { Seemed solid like a living being } \\
12 \% \text { Semi-transparent (objects behind the } \\
\text { deceased were visible) } \\
11 \% \text { A foggy silhouette } \\
15 \% \text { Other }\end{array}$ \\
\hline $\begin{array}{l}\text { 48. Did the deceased look the same as they did at the } \\
\text { hour of their death (visibly marked by their illness, } \\
\text { by the accident that caused their death, etc.) or didn't } \\
\text { they look the same? }\end{array}$ & $\begin{array}{l}17 \% \text { Yes, looked the same } \\
55 \% \text { No, looked different } \\
7 \% \text { Unsure } \\
20 \% \text { Other }\end{array}$ \\
\hline $\begin{array}{l}\text { 50. Was the deceased immediately familiar to you, } \\
\text { e.g., wearing their favorite clothes, behaving in a } \\
\text { familiar way, etc.? }\end{array}$ & $\begin{array}{l}76 \% \text { Yes } \\
17 \% \text { No } \\
7 \% \text { Unsure }\end{array}$ \\
\hline $\begin{array}{l}\text { 51. Did the deceased seem to be the same age as } \\
\text { when he/she died? }\end{array}$ & $\begin{array}{l}51 \% \text { Same age } \\
32 \% \text { Younger } \\
1 \% \text { Older } \\
16 \% \text { Unsure } \\
\end{array}$ \\
\hline $\begin{array}{l}\text { 52. Did the deceased seem brighter than their } \\
\text { environment, e.g. was there a light that surrounded } \\
\text { them or emanated from them? }\end{array}$ & $\begin{array}{l}35 \% \text { Yes } \\
54 \% \text { No } \\
11 \% \text { Unsure } \\
\end{array}$ \\
\hline 53. How did the deceased appear? & $\begin{array}{l}28 \% \text { Materializing right before my eyes } \\
60 \% \text { Already there when I perceived them } \\
12 \% \text { Unsure }\end{array}$ \\
\hline 54. Was the deceased: & $\begin{array}{l}\text { 19\% Completely motionless } \\
29 \% \text { Quite static } \\
30 \% \text { Moving about the environment } \\
16 \% \text { Quite animated (gesticulating) } \\
6 \% \text { Unsure }\end{array}$ \\
\hline 55. How did the deceased disappear? & $\begin{array}{l}15 \% \text { Fading gradually } \\
28 \% \text { Dissolving instantly } \\
18 \% \text { Not there anymore when I blinked } \\
11 \% \text { Unsure } \\
28 \% \text { Other }\end{array}$ \\
\hline
\end{tabular}

The data revealed a continuum in the reported perceptions, from an internal to external focus of experience. Of ADCs that had an internal focus, one woman shared that she saw the deceased "in her mind's eye" while traveling to be with her family as her mother was dying. She said,

At about 10:50 pm that night, while on the plane, I began to weep a little, and must have gone into a light meditative state during this time. While in this state of mind, and in my mind's eye, I saw my Mother. She was wearing a pale blue night gown and walking across a theatre stage from left to right. The theatre had thick velvet curtains and there were clouds of smoke around her ankles. Suddenly, the words "Now I can rest" popped into my mind. I felt a kiss on my forehead. An incredible sense of peace filled me, and I felt as if I no longer needed to fear Death. I remember coming out of this state of mind, wiping my tears away, and looking at my watch. It 
was 11:10 pm--twenty minutes had passed. When I arrived at the hospital and told my family about what happened, they told me that they had gathered around my mother's hospital bed, telling her it was all right to "go" and for her to "go find" me and my sister who could not come to Oregon. My younger sister told me that as Mom took her last breath that she had looked at my father's watch to note the time. It was about 11:08 pm, meaning that Mom "found" me within minutes of her physical passing. (E87)

Along this continuum from internal to external focus of the experience, $11 \%$ saw the deceased as a foggy silhouette. One respondent described her experience as "a silhouette filled with light which surrounded her" (E361). Another said, "He was grey, like smoke but perfectly recognizable, and standing on the lawn" (F345). And another said, "Within a day or 2 after my father's passing, he appeared one night by my bed to say goodbye. I could only see him from the waist up. He was more of a silhouette, but I could still see his piercing blue eyes, just looking at me" (E133). An additional 12\% of the respondents had an ADC in which the deceased was seen as semi-transparent, with objects behind them being visible. One participant described the deceased saying, "She had the appearance of a human being, but not solid like a living being" (F69).

Almost two-thirds (62\%) of respondents said that the person seemed solid like a living being. One person noted, "He was more than solid, he was real, radiant, happy" (F267). Another said, "Solid, since I took him several times in my arms, and the same consistency as when living" (F328). In this case the experience was just like in 3-D reality, and possibly even hyper-real. One example that expresses this clearly is of a man who saw his grandmother early one morning years after she had died:

On June 12th 2012, I was awakened around 6 am in the morning. I saw someone walking on my front porch through my bedroom window. I thought, "who would be here this early?" I got dressed and went to the front door. I opened the door and saw a woman with her back to me on my left, crying. I asked if she was ok. She turned around and it was my grandmother from my father's side of the family. I was in shock to see her. She spoke and asked me for forgiveness and apologized for no longer talking to me after my father had passed away. I told her it was okay and I forgave her. She walked towards me and we hugged. I felt her frail body hug me and I hugged her back. I felt her clothes, her smell and she thanked me as we hugged. I felt this most intense feeling of love. I started to cry. She then started to turn into this bright white light. I had to close my eyes due to it being so bright. I could see the light fading away through my eye lids. The feeling of her started to slowly leave. I opened my eyes and she was gone. I was standing there with my arms still looking like I was hugging someone. I was in shock. I went back into the house and laid on my bed and my wife woke up. I told her what happened [...] My grandmother had been dead for about 7 years. (E193)

Finally, $15 \%$ of the visual perceptions could not be classified as solid, semi-transparent or a silhouette. These included holographic images, an orb of light, a luminous form, a shadow, and an image projected on a screen. One person said, "It looked like a photo of her surrounded by a circle of sun rays" (E165). One person noted a dynamic evolution 
of the perception, beginning with a hazy form which solidified gradually, going through a silhouette stage, and then taking on the perception of a solid living person. These data illustrate the diversity of ways that the deceased appeared in visual ADCs.

Regarding other details of the visual experience, the majority of respondents saw the whole body of the deceased, as case E193, above, exemplifies, but 25\% saw only the upper portion of the body. In most cases the deceased was in the center of the visual field $(74 \%)$ and within reaching distance (62\%). One woman said, "When I just saw his face, his was to my left, large \& high above me... he actually materialized right in front of my eyes... surreal. In the second part, he was a solid living being - I saw him 'trip' down into a room I was in, and I crouched down beside him" (E63).

Our data also show that the deceased typically (55\%) looked different in the ADC than at the hour of death, often showing themselves in radiant health. For example, one woman said, "My son died from cancer; when I saw him, he was in perfect health and beautiful" (E230). In the majority of cases (51\%), the individual appeared at about the age of passing but for other cases the deceased were apparently capable of appearing to the loved one at a variety of ages. They often showed themselves at the prime of their life, or even as a young person. In fact, $32 \%$ of the deceased looked younger and only $1 \%$ seemed older than when they died. One person noted, "My father looked younger - in his teens prior to his accident that left him a quadriplegic" (E107). Another said, "Although she died at age 82, in the vision I saw her as I had known her in her 30s, radiantly healthy" (E165).

Though there were many ways that the percipient identified the deceased, one contribution was through the clothes they wore. Interestingly, about $76 \%$ were wearing their favorite clothes and behaving in their normal way. In fact, some wore clothes that were of special significance to the percipient. For example, one person noted, she looked like "she did when I last saw her. She was wearing her favorite London Fog trench coat" (E193). And another said, "He looked normally alive and wearing a light grey 'leisure suit' that I'd bought him years before he died" (E318). Another remembered that her boyfriend's clothes were of another fashion era. She said, "He passed in Viet Nam, but he and his friends were dressed in a suit and what struck me 25 years later was that he was wearing the skinny ties the guys wore in the 60s. He passed in 1966. I had forgotten that piece of fashion until I saw him" (E8).

Another interesting aspect of the visual ADC was how the deceased appeared and disappeared; for $60 \%$, the deceased was already there when the respondent first noticed them, while for $28 \%$ they materialized right before the respondent's eyes. This happened in many ways. For example, some respondents said that they were awakened 
at night by the deceased. In other cases, the deceased was already present when the respondent suddenly became aware of their presence.

In addition, the deceased could simply enter or leave the presence of the respondent, by walking into or out of the room, or walking down the road ("simply turned and walked out of my sight" [E295]; "got up and walked out the wall" [E215]). For 28\% of respondents the deceased dissolved instantly, for 15\% they faded away gradually, and for $18 \%$ they were not there anymore when the percipient blinked ("when I looked away, he was gone" [E270]). Here is one complete example, a visit by a woman's twin sister who was deceased. She said,

A few days before our birthday several years later I was spending the night at our parents'. It was late at night, rather early in the morning, and I was asleep in their guestroom. Suddenly, I was awakened from a deep slumber by the feel of two hands encircling both my wrists. I found myself (who has never sleep-walked and does not take sleeping pills) by the side of the bed with my hands holding Mary's wrists and hers holding mine. We were both wearing navy silk lounging robes that Mom and Dad had given me since her death. She looked radiant, with clear shining eyes... and perfect hair. I said to her "I just talked to Alice, to David and to Kerry, you should contact them." She said, "I will." Almost right away it occurred to me "wait, she is dead." And then I "came to." I was standing by the bed, faced in the direction I had been when facing her. I did not experience this as a dream, I experienced this as reality. (E265)

\section{Tactile perceptions: feeling a physical touch}

As seen in Table 4, the responses to questions regarding the nature of the tactile experience indicate that nearly half $(48 \%)$ of the persons surveyed experienced a tactile aspect to their ADC and the touch was both familiar and typical for the deceased (55\%). The touch involved some type of physical contact on a part of the body (the hair, face, shoulders, arm, hand, neck, torso, legs, feet were all mentioned). It could be a touch, a feeling of pressure, a kiss or caress, a hand placed on the shoulder, or a true embrace. One person remarked, "She felt like a living person when we embraced in a hug, I felt her clothes, her frail body, and hair" (E193). Another young man said rather humorously,

It was as if his hand suddenly grabbed my lower leg, ankle area. It felt very physical not hurting at all just reminiscent of what he used to do when we were kids and growing up. It was his playfulness side. Also he wanted us to know he was there with us even though he had already died. (E190)

\begin{tabular}{|l|c|}
\hline Table 4. Physical Contact with the Deceased & Percent Response \\
\hline Q 33. Did you feel a physical contact initiated by the deceased? (e.g. & $48 \%$ Yes \\
you felt that the deceased was touching your hand, wrapping & $47 \%$ No \\
his/her arm around your shoulders, etc.) & $5 \%$ Unsure \\
\hline Q 35. Was this contact familiar to you / was it typical for the & $55 \%$ Yes \\
deceased? & $34 \%$ No \\
\hline
\end{tabular}




\begin{tabular}{|l|c|}
\hline $\begin{array}{l}\text { Q 36-37. Did you feel that this contact was transmitting some sort of } \\
\text { message? If, yes please specify. }\end{array}$ & $80 \%$ Yes \\
& $10 \%$ No \\
\hline Q 61. Did you try to touch the deceased? & $10 \%$ Unsure \\
& $26 \%$ Yes \\
& $72 \%$ No \\
\hline Q 62. If yes, could you grasp the deceased/did you feel a & $2 \%$ Unsure \\
resistance/matter? & $43 \%$ Yes \\
& $42 \%$ No \\
\hline
\end{tabular}

The percipients reported being comforted by the touch and generally recognized their loved one immediately because the touch was so familiar. One respondent commented, "It was almost indescribable. It was his touch, his sense of humor; everything I remembered about him that I had forgotten came rushing back" (E8). Another woman expressed how important the physical touch of her mother was for her:

When I lay on my bed to take a siesta after being very tired, I sensed a caress on my arms. Since mother had left, I often said that it was the physical contact that I missed the most, because mother had incredibly soft hands. And I truly sensed her hands caressing me. (F292)

Some individuals felt a flow of energy as part of the gesture. One woman shared, "I felt most profoundly in all my being an enormous energy moving through my spine" (F152). Another said, [There was a] "wonderful flooding of energy all over, and on specific body parts when touching, caressing, kissing me" (E211).

When respondents were asked if they had tried to touch the deceased, only $26 \%$ reported trying to do so. Of those that tried, a little under half (43\%) were able to grasp the deceased, and felt resistance to their touch, as if they were touching a material being. One person said of his experience, "I was in a hypnagogic state right before dozing off on the couch. I felt my deceased son wrap his arms around me from behind. I was able to kiss his left hand and then his right arm. I could feel the hair on his arms and told him that I loved him. Then he left" (E104). Another person said, "We hugged in an intense and joyous embrace" (E8), and another said, "His hand felt the same to me as it did when he was living, yet I knew he was dead" (E40).

Others had a different experience. One said," I see my hand touching her hand, but I sense nothing" (F14). Another respondent said, "He jumped out the way making it very clear not to touch him, as our vibrations weren't compatible yet" (E82).

When respondents were asked if they thought the deceased was conveying a message through the touch, $80 \%$ replied in agreement. The messages typically conveyed love and reassurance that the beloved was still with them but in a different form. One person said, "He was letting me know that he was there, and I was not imagining it." (E66) 


\section{Auditory perceptions - Hearing a voice externally or internally}

Table 5 shows that $44 \%$ of the respondents reported hearing the deceased, and these communications came in two forms. Close to half $(48 \%)$ said that the voice came from outside them, as if in a conversation between two people, while $57 \%$ reported perceiving the communication telepathically, that is without an external sound. The percentages exceed $100 \%$ in this case, because many people had more than one ADC and received communications in both forms. Both types of auditory communication were recognized immediately either by the tone of the voice, or the characteristic way that the deceased expressed themselves. Among those who reported hearing an external voice, two-thirds (68\%) said the voice heard was the same as the one the deceased had while living, though in some cases, it was the voice they had when healthy. For example, one person said, "It was the same as when he was healthy before the stroke - he had aphasia after the stroke, and so that was not the version of him I interacted with" (E24).

\begin{tabular}{|l|l|}
\hline Table 5. Hearing the Deceased & Percent response \\
\hline Q 27. Did you hear the deceased? & $44 \%$ Yes \\
& $50 \%$ No \\
& $6 \%$ Unsure \\
\hline $\begin{array}{l}\text { Q 28. Did the voice come to you from the outside, as in a } \\
\text { conversation between living persons? }\end{array}$ & $48 \%$ Yes \\
& $40 \%$ No \\
& $12 \%$ Unsure \\
\hline Q 29. Was the voice the same or different from the one the & $68 \%$ The same \\
deceased had while alive? If different please describe. & $15 \%$ Different \\
& $17 \%$ Unsure \\
\hline Q 31. Was the communication without an external sound, & $57 \%$ Yes \\
as if perceived telepathically? & $32 \%$ No \\
& $11 \%$ Unsure \\
\hline Q 32. Was the perceived communication different from a & $87 \%$ Yes \\
thought? & $7 \%$ No \\
& $6 \%$ Unsure \\
\hline
\end{tabular}

In some cases, the individual hadn't spoken during their lifetime. A mother noted, "My daughter died at the age of two days, so she didn't yet know how to speak; the voice that I perceived seemed neither masculine nor feminine" (F363).

Others were humorous and made the recipient laugh. For example, an individual responded,

Early in our relationship he tried to interest me in opera, to no avail. After he passed to Spirit two friends wanted to go to see La Bohème in English at the Coliseum, London. I went with them and was moved to tears by the story and Mimi's death, which had parallels with my life-partner's. As I left the theater with the friends, me in tears, the telepathic message came into my head, so 
typical of [him]: 'I had to f-ing die to get you to appreciate opera!' Instantly my tears cleared up and I burst out laughing. (E20)

There were many variations on the sound of the voice. One person said, "It was more like a whisper, very subtle" (F100). Another said, "She sounded as if she was talking under water" (E373), and in one case, the sound was not of a voice but of footsteps. The respondent said, Some days ( 10) after my father died, I was at his house. I was in the kitchen and the house was quiet (late afternoon). I heard him come through the door and do a walk through the house. It was his gait, his movement up the steps. I heard the footsteps through the house, room by room. It was immediately obvious to me that he was doing a final walk through his house. After a couple of minutes, he exited the front door. It was clear that there was a shift in energy, a release. The experience was audio. It did not frighten me because the pace and movement of the sound was so like him. (E61)

And when respondents were asked if this communication was the same or different from a thought, $87 \%$ said that it was different from a thought.

\section{Olfactory perceptions - noting a fragrance characteristic of the deceased}

Olfactory perceptions associated with ADCs occurred when the contact with the deceased include smelling a fragrance that was associated with them. When asked if their ADC involved a fragrance, 28\% said that it did (see Table 6). The fragrances typically included after shave lotion, a typical body scent, perfume or soap, but many odors were noted in the descriptions, including tobacco, food and flowers. Here are some examples of what different respondents shared: "the odor of the pipe of my father" (F48), "the odor of his hair" (F50), "his perfume" (F298), "the perfume of his shampoo" (F90), the "perfume and aroma of crêpes, his favorite dish" (F97), "for Papa it was the smell of brioche and coffee" (F199), "tobacco" (F255), "the smell of roses" (F324), the "smell of my sons after returning home from work" (E136).

More than half of respondents (60\%) felt that a message was being conveyed through the fragrance they perceived. Most people said it was the deceased person's way of letting them know they were still with them. One person said, "Everyone knew her scent, so it was her way of proving to her entire family when they came over that she was still there" (E147).

\begin{tabular}{|l|l|}
\hline \multicolumn{1}{|c|}{ Table 6. Olfactory Perceptions Related to the Deceased } & Percent Response \\
\hline Q 64. Did you smell a fragrance characteristic of the deceased which & $28 \%$ Yes \\
made you think he/she was present? If yes, describe the fragrance. & $67 \%$ No \\
& $5 \%$ Unsure \\
\hline Q 66. Did you feel that the deceased was conveying a message to you by & $60 \%$ Yes \\
way of this fragrance? If yes, please specify. & $20 \%$ No \\
& $20 \%$ Unsure \\
\hline
\end{tabular}




\section{Previously unknown information communicated within the ADC to the percipient}

The second and third hypotheses regarding the nature of ADCs, discussed earlier, proposed that they represent an actual communication (with information transfer) between the deceased and the percipient that is telepathically or physically perceived. To further examine these hypotheses, we have included data concerning the possibility of this information transfer.

In response to the question: "Did you receive any information unknown to you previously?" $24 \%$ (i.e., 236 persons) responded in the affirmative, $69 \%$ responded that they had not, and $7 \%$ were unsure. Twenty-three persons declined to answer the question. For those who described the information they received, in some cases, this information related to the passing of the deceased. For example, a woman was told by her grandfather in an ADC at 6 am that he was leaving. She says,

I awoke suddenly for no reason from a good sleep and saw my grandfather standing at the side of my bed. He seemed slightly younger, healthier and radiating pure love. He smiled at me and said, "I'm going away my wee dove" (his pet name for me). I smiled back at him and looked at my alarm clock; it was 06.00 . Then he was gone. It didn't occur to me to ask my grandfather where he was going or why he was in my room at 6 in the morning. I just slipped back into a peaceful sleep. I was later wakened by the telephone ringing and my grandmother sobbing on the phone that papa was dead. His death certificate later stated [that the] approximate time of death [was] $06.00 \mathrm{am}$. (E268)

Information was also given regarding the location of items that had been lost or hidden [e.g., the location of a lost ring (S83), or hidden documents (S90)]. One respondent shared,

My deceased friend came through with a message for his wife. It started with "tell Beverley the key is" and we all assumed it would be love or something similar. Instead, he went on to tell us where a particular key was in his former home.... His daughter, who was living in Abu Dabi, is a very close friend of my daughter so we decided it would be best to let her know and decide whether to pass it on to her grieving mother. So we rang her - she rang her mother who said "I have been looking for that key all weekend!" It was the key to the gun cupboard and she wanted a friend to take the gun away. This proved to me that the message was real, not my imagination as I had no idea they had a gun or a key or a gun cupboard! (E210)

Another responded,

In the months after he passed to Spirit a friend told me my partner had been given two negatives of photos of me and my partner. I had no idea he had these negatives. The friend wanted them back to make copies. I searched our box of negatives in vain. So, writing a posthumous letter to my same-sex life-partner, I said if he'd been given the negatives could he somehow tell me where they were. Next day in the kitchen the clear telepathic sentence came into my head: 'The negatives are on the top shelf of the larder'. Thinking this was ridiculous, I nevertheless climbed on a chair and there were the two negatives in an envelope! (E20) 


\section{Discussion}

The primary purpose of this study was to create a detailed characterization of the nature of the sensory perceptions associated with after-death communication. One significant finding from this study was that, according to the question asked, 87\% (hearing a voice) and 61\% (sensing a presence) of respondents reported that ADC perceptions were distinctly different from simple thoughts about the deceased. Specifically, relative distribution across the senses was $46 \%$ visual, $44 \%$ auditory, $48 \%$ touch, and $28 \%$ olfactory. Finally, $34 \%$ sensed the presence of the deceased without input from the five senses. These results support and extend the results of previous studies in this area. It is interesting that of 35 ADC studies that were reviewed by Streit$\operatorname{Horn}^{3}$ (2011) only about half discussed sensory types of ADCs and typically limited their analysis to the relative prevalence of ADCs involving each of the senses. Within these studies there was considerable variability in the relative distribution of ADCs perceived across the senses. For example, Greeley, ${ }^{23}$ Haraldsson $^{8}$ and Olson et al., ${ }^{24}$ identified visual as the most common type of ADC while Grimby ${ }^{25-26}$ found sense of presence to be most common.

One aspect of many ADCs is the sense that a message is being received. In the current study, and according to the question asked, $75 \%$ (sensing a presence), $80 \%$ (tactile ADC), $80 \%$ (visual ADC), and 60\% (olfactory ADC) of respondents stated that they had received a message and it was often perceived not only through hearing and seeing the deceased, but even when the perception was a simple sense of presence, fragrance, or touch. In contrast, Haraldsson ${ }^{8}$ noted that only $25 \%$ of respondents received a specific message while an additional $32 \%$ felt the simple appearance of the deceased conveyed a message. This variability across studies can be explained in part as an artifact of the different methods used. In general surveys, respondents may be willing to share more trivial or less evidential experiences, but where they have to volunteer their experiences (particularly with an extensive questionnaire as here) those with experiences that they see as less persuasive to others may be more reticent to participate or more inclined to drop out of participation before completing the questionnaire. The variability also may be due to the wide range of perceptual abilities in the general population, and sampling of small data sets by the various studies.

\section{Internalization vs externalization of the perceptions}

Gurney et al. ${ }^{10}$ had noted within the range of ADC descriptions, what they called internalization vs. externalization of perceptions. They stated that these ranged in varying degrees from a purely internal representation as is seen by the "mind's eye," to an actual percept, which though it also may come through the mind, appears to take 
place in the physical world and in relationship to other objects in the percipient's vicinity. Through a detailed examination of perceptual correlates of ADCs we examined the extent to which data supported one or more of three hypotheses that could contribute to an explanation of this phenomenon. These include the extent to which perceptions appeared to be occurring internally, as a thought (hypothesis 1), as if telepathically through the mind (hypothesis 2), or perceived as being sensed externally through the senses or through extra-sensory means in the physical environment (hypothesis 3).

In order to explore the relative validity of these hypotheses, the questionnaire asked specifically about the level of consistency of the deceased's visual appearance, in three steps, from a foggy silhouette, to semi-transparent to what seemed like a solid living human being. It also allowed the respondent to check "other" if the visual appearance didn't fit into these three categories. Interestingly, while $12 \%$ of perceptions were semitransparent and $11 \%$ were of a foggy silhouette, almost two thirds of respondents (62\%) perceived a solid living being. Respondents often reported that visual perceptions of the deceased seemed more real than a day-to-day interaction; it seemed hyper-real. Haraldsson ${ }^{8}$ similarly found that $73 \%$ of percipients believed the deceased had been "physically present," which was interpreted as being present in the flesh.

The nuanced nature of visual perceptions was also revealed by the variety of descriptions. While many could be categorized within this continuum of internal to external perceptions, others fell outside this continuum. For example, as a holographic image, an orb of light, a luminous form, a shadow, and the appearance of an image projected on a screen. These variations, as well as variations in age, health, and dress compared to the circumstances of death are similar to those found in many other research accounts, ,10,27-32 and raise questions about the origin and nature of these perceptions.

One way to examine the extent to which the ADC was perceived as "real" is to ask the extent to which the perception was similar to or different from a thought (hypothesis 1). The vast majority of respondents (87\%) felt that the auditory communications were different from thoughts. Of these respondents, $48 \%$ perceived ADCs as being external, while $57 \%$ noted that they could also be telepathic in some instances. Likewise, with perceptions of touch, the extent to which it felt like a physical perception, rather than simply imagination was probed by asking if the respondent felt resistance when they touched the deceased. Forty-three percent of respondents felt resistance to their touch and noted in their descriptions that the skin, hair or clothing felt like it had in the person's physical life. This sense of resistance to touch is evidence that contributes to the support of hypothesis 3. 
Being aware of how solid and real many of these experiences appeared to be, it is also interesting to see, paradoxically, that in $28 \%$ of the cases the experience dissolved instantly, was gone in the blink of an eye $(18 \%)$, or slowly faded $(15 \%)$, contrary to what would happen in a normal interaction. This was often startling to the percipient. One person noted, when hugging his grandmother and feeling her frail body hugging him back, "the feeling of her started to slowly leave. I opened my eyes and she was gone. I was standing there with my arms still looking like I was hugging someone."

Hypothesis 1 proposes that the sensory phenomena associated with ADCs are hallucinations (i.e., an experience in which you see, hear, feel or smell something that does not exist), and these hallucinations may be the result of faulty brain activity..$^{29-30,33}$ However, evidence has been published over the last decades both in near-death experience research and ADC research showing accounts of verified awareness of physical events or reception of information that appeared to occur through other than the five senses. These include 1) the verified perceptions occurring during near-death experiences when the individual underwent cardiac arrest, flat EEG, and thus the inability to perceive events through the five senses, ${ }^{34-36}$ as well as 2) verified accounts of information that no one else had knowledge of, being conveyed from the perceived deceased in ADCs. ${ }^{4,8}$ Our collection also includes cases in which percipients received information during an ADC that no one else had prior knowledge of, including the location of hidden objects and documents (E20, E210, S83, S90). This ADC information allowed the solution of specific problems, e.g., allowing lost objects to be found. Such evidence is a challenge to hypothesis 1 .

Guggenheim and Guggenheim ${ }^{4}$ in a study of over 3,300 first-hand accounts of ADC also give many similar examples of these veridical communications, including one in which a grandmother who died of a stroke helped solve the following mystery. When the family was going through things after her death, they realized one of the family guns, an old army rifle that had hand-carving, was missing. After looking everywhere, the daughter took a nap and had a dream which she interpreted as her Grandma Davis coming to her to tell her the rifle was between the mattress and the box-spring of the bed she was sleeping on. She woke up, and called her husband to come into the room, pulled up the mattress and there it was.

In conclusion, the current study aimed to broaden our understanding of the nature of ADCs by 1) exploring the scientific validity of studies related to anomalous events like ADCs, 2) improving our culture's understanding of ADCs by demystifying them, and 3) promoting the acceptance of the ADC phenomenon and providing support to persons who experience them. Results indicate that ADCs are experienced across a 
range of modalities and often are perceived as external and having properties of the material world (e.g., solidity, tactile qualities). Even the more nebulous 'sense of presence' cases are perceived as having a distinct location in space and as being identifiable as a specific deceased presence despite the lack of sensory cues. These elements are more compatible with hypotheses 2 and 3 than hypothesis 1.

\section{Limitations}

There are two basic approaches to collecting cases regarding ADCs and other similar phenomena. One approach involves extensive investigation of reported cases (e.g., Sidgwick et al., ${ }^{13}$ Stevenson ${ }^{37}$ ), while a second approach involves more comprehensive collections of cases to look for patterns across cases rather than treating individual cases as evidential in themselves (e.g., Rhine ${ }^{38}$ ). They each have their strengths, in terms of the depth vs. breadth of the data collected. This study was a survey of the second type, involving self-reports collected through questionnaires from persons who believed they had experienced an ADC. Thus, in this study the veracity of statements by the percipients related to information given them by the deceased, that they say was subsequently shown to be true, has not been verified through secondary sources. We recommend that additional studies in the area incorporate information from secondary sources to create more depth in data analysis and determine secondary support for the veracity of statements. Another limitation is that, as this was not an interview-based study, but a survey based on a questionnaire completed anonymously, the respondents could not be contacted for information to further clarify their ADC. Survey development and piloting methods were not used in this study.

Funding: This work was supported by a foundation that wishes to remain anonymous. The funding organization had no influence on the final research design, data collection, analysis, interpretation of data, the writing of the report or the decision to submit the article for publication.

\section{References}

1. Steffen E, Coyle A. Sense of presence experiences and meaning-making in bereavement: A qualitative analysis. Death Stud. 2011;35(7):579-609. doi: 10.1080/07481187.2011.584758.

2. Conant RD. Memories of the death and life of a spouse: The role of images and sense of presence in grief. In: Klass D, Silverman PR, Nickman SL, eds. Continuing Bonds: New understandings of Grief. Taylor \& Francis. 1996:3-27. 
3. Streit-Horn J. A Systematic Review of Research on After-Death Communication (ADC). Dissertation. University of North Texas; 2011.

4. Guggenheim B, Guggenheim J. Hello from Heaven! A New Field of Research, After-Death Communication, Confirms that Life and Love are Eternal. New York, NY: Bantam Books; 1995.

5. LaGrand LE. The nature and therapeutic implications of the extraordinary experiences of the bereaved. J Near-Death Stud. 2005;24:3-19.

6. Burton J. Contact with the dead: A common experience? Fate. 1982;35(4):65-73.

7. Castelnovo A, Cavallotti S, Gambini O, D'Agostino A. Post-bereavement hallucinatory experiences: A critical overview of population and clinical studies. J Affect Disord. 2015;186:266-74. doi: 10.1016/j.jad.2015.07.032.

8. Haraldsson E. The Departed Among the Living. An Investigative Study of Afterlife Encounters. Guildford, UK: White Crow Books; 2012.

9. Kalish RA, Reynolds DK. Phenomenological reality and post-death contact. J Sci Study Relig. 1973;12(2):209-221.

10. Gurney E, Myers FWH, Podmore F. Phantasms of the Living. London: Trubner; 1886.

11. Gurney E, Myers FWH. On apparitions occurring soon after death. Proc Soc Psychic Res. 1887-88;5:403-485.

12. Haraldsson E. Survey of claimed encounters with the death. Omega J Death Dying. 1988-89;19:103-113.

13. Sidgwick H, Sidgwick E, Johnson A. Report on the census of hallucinations. Proc Soc Psychic Res. 1894;10:25-422.

14. Beischel J. Spontaneous, facilitated, assisted, and requested after-death communication experiences and their impact on grief. Threshold: J Interdisc Consc Stud. 2019;3(1):1-32.

15. Chan CL, Chow AY, Ho SM, et al. The experience of Chinese bereaved persons: A preliminary study of meaning making and continuing bonds. Death Stud. 2005;29(10): 923-947. 
16. Krippner, S. (2006). Getting through the grief: After-death communication experiences and their effects on experients. In L. Storm \& M.A. Thalbourne (Eds.), The survival of human consciousness (pp. 174-193). Jefferson, NC: McFarland.

17. Cooper CE. Spontaneous Post-Death Experiences and the Cognition of Hope: An Examination of Bereavement and Recovery. Unpublished $\mathrm{PhD}$ thesis, University of Northampton, Northampton, UK; 2017.

18. Rees WD. The hallucinations of widowhood. BMJ. 1971;4:37-41.

19. Houck JA. The universal, multiple, and exclusive experiences of after-death communication. J Near-Death Stud. 2005;24(2):117-127.

20. Baruss I, Mossbridge J. Transcendent Mind. Rethinking the Science of Consciousness. Washington, DC: APA; 2017.

21. Schwartz S, Woollacott M, Schwartz G. Is Consciousness Primary? Battleground, WA: AAPS Press; 2020.

22. Castro M, Burrows R, Wooffitt R. The paranormal is (still) normal: The sociological implications of a survey of paranormal experiences in Great Britain. Sociol Res Online. 2014;19(3):1-15. https://doi.org/10.5153/sro.3355.

23. Greeley A. Mysticism goes mainstream. Am Health. 1987; Jan/Feb: 47-49.

24. Olson PR, Suddeth JA, Peterson PJ, Egelhoff C. Hallucinations and widowhood. J Am Geriatr Soc. 1985;33(8):543-547.

25. Grimby A. Bereavement among elderly people: Grief reactions, postbereavement hallucinations and quality of life. Acta Psychiatr Scand. 1993;87(1):72-80.

26. Grimby A. Hallucinations following the loss of a spouse: Common and normal events among the elderly. J Clin Geropsych. 1998;4(1):65-74.

27. Devers E. Experiencing the Deceased: Reconciling the Extraordinary. Dissertation Abstracts International. 1994; B 56/11. (UMI No. 9606770).

28. Devers E. Goodbye again: Experiences with Departed Loved Ones. Kansas City, MO: Universal Press Syndicate; 1997. 
29. Kamp KS, O'Connor M, Spindler H, Moskowitz A. Bereavement hallucinations after the loss of a spouse: Associations with psychopathological measures, personality and coping style. Death Stud. 2019;43(4):260-269. doi: 10.1080/07481187.2018.1458759.

30. Kamp KS, Steffen EM, Alderson-Day B, Allen P, Austad A, et al. Sensory and quasisensory experiences of the deceased in bereavement: An interdisciplinary and integrative review. Schizophr Bull. 2020. doi:10.1093/schbul/sbaa113.

31. Bennett G, Bennett KM. The presence of the dead: An empirical study. Mortality. 2000;5(2):139-157.

32. Keen C, Murray CD, Payne S. A qualitative exploration of sensing the presence of the deceased following bereavement. Mortality. 2013:18(4):339-357.

33. Kersting A. The psychodynamics of grief hallucinations - a psychopathological phenomenon of normal and pathological grief. Psychopathol. 2004;37(1):50-51.

34. Greyson B. Seeing dead people not known to have died: "Peak in Darien" experiences. Anthropol Humanism. 2010;35(2):159-171.

35. Cook EW, Greyson B, Stevenson I. Do any near-death experiences provide evidence for the survival of human personality? Relevant features and illustrative case reports. J Sci Explor. 1998;12:377-406.

36. van Lommel P, van Wees R, Meyers V, Elfferich I. Near-death experience in survivors of cardiac arrest: a prospective study in the Netherlands. Lancet. 2001;358(9298):2039-2045.

37. Stevenson I. The explanatory value of the idea of reincarnation. J Nerv Ment Dis. 1977;164:305-326.

38. Rhine LE. ESP in Life and Lab: Tracing Hidden Channels. New York: Macmillan; 1967. 